\title{
Kenya adolescent sexual and reproductive health policy
}

Ministry of Health Kenya

Follow this and additional works at: https://knowledgecommons.popcouncil.org/departments_sbsr-rh

Part of the Demography, Population, and Ecology Commons, Family, Life Course, and Society Commons, Health Policy Commons, International Public Health Commons, Maternal and Child Health Commons, and the Women's Health Commons How does access to this work benefit you? Let us know!

\section{Recommended Citation}

Ministry of Health Kenya. 2015. "Kenya adolescent sexual and reproductive health policy." Nairobi: Ministry of Health, Kenya. 
REPUBLIC OF KENYA



MINISTRY OF HEALTH

\section{NATIONALADOLESCENT}

SEXUALAND REPRODUCTIVE

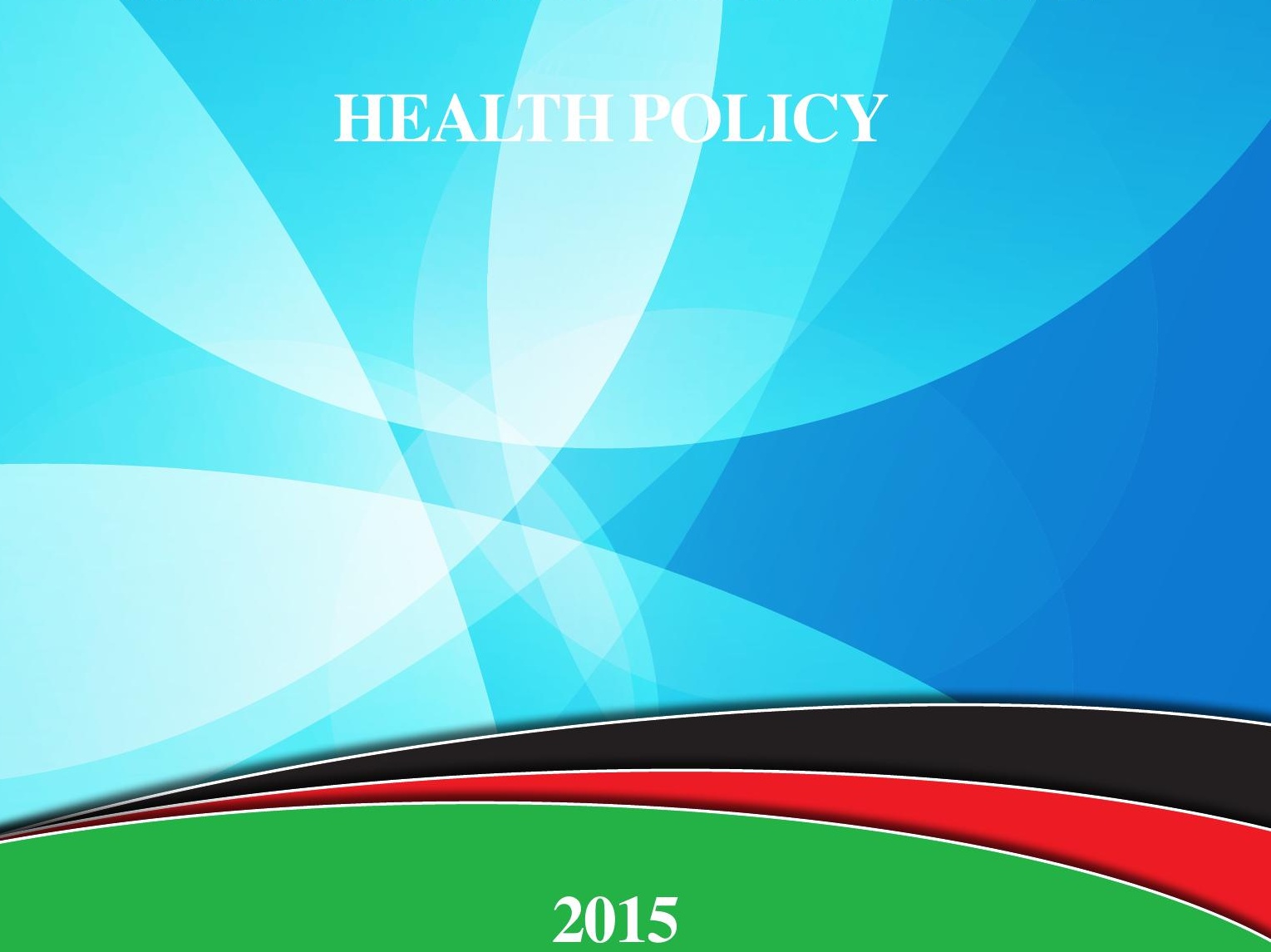





\section{TABLE OF CONTENTS}

Acknowledgement iv

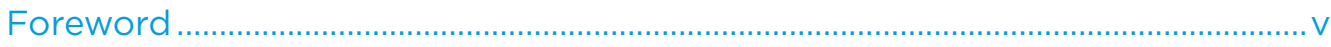

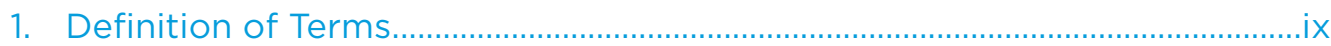

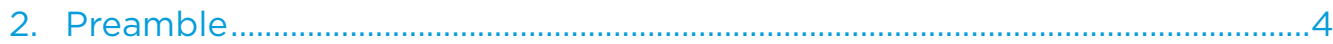

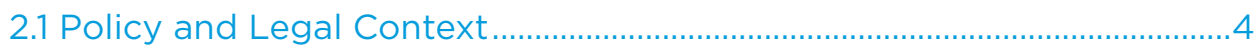



2.3 National Adolescent Sexual and Reproductive Health Policy.................6

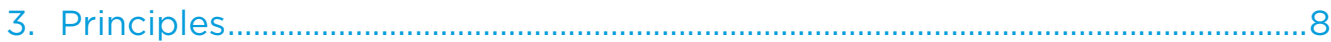

4. Sexual and Reproductive Health Status of Adolescents in Kenya..................9



5.1 ASRH Policy Goal, Objectives, Priority Areas and Actions ...................... 16

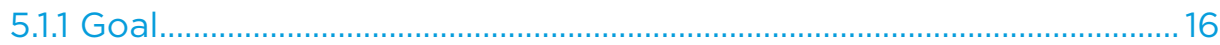

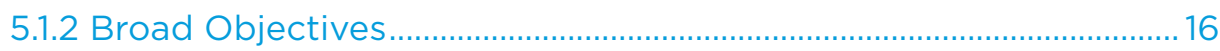





6.1 Management and Coordination .................................................................... 21

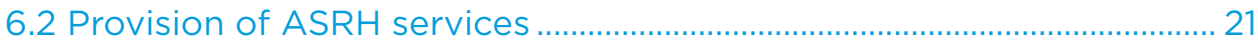

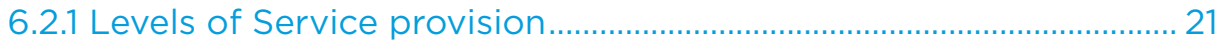

6.2.2 Standards for Provision of Adolescent-Friendly SRH Services....22

6.2.3 Health Systems Requirements................................................................ 22

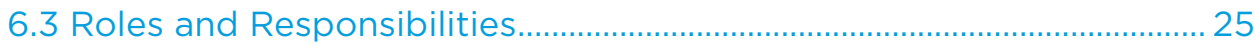

6.3.1 Role of the Ministry of Health at National Level.............................. 25

6.3.2 Role of Ministry of Health at County Level......................................... 26

6.4 Monitoring and Evaluation......................................................................... 31



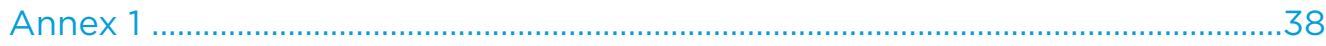




\section{ACKNOWLEDGEMENT}

The review and revision of the National Adolescent Sexual and Reproductive Health Policy involved in-depth consultations with a wide range of stakeholders through literature review, interviews, consultative meetings and reviews of the various drafts of the Policy.

The Ministry of Health feels greatly indebted to individuals and organizations who contributed in one way or another to this elaborate process. Specifically the Ministry would like to thank Leah Rotich - Education Secretary, Dr. Patrick Amoth - Head of the Division of Family Health (DFH), and Dr. Kigen Bartilol - Head of the Reproductive and Maternal Health Services Unit, who gave valuable inputs and support to the review and revision exercise.

We further wish to extend our gratitude to Dr. Jeanne Patrick, Anne Njeru, Mary Magubo and Batula Abdi for leading the process and working with Maureen A. Kuyoh, the lead consultant, to collect, synthesize and incorporate stakeholders' views at every stage of revising the Policy.

The Ministry of Health would like to further recognize the policy review and revision taskforce members of the Adolescent Sexual Reproductive Health Technical Working Group (ASRH TWG) who worked tirelessly with the consultant to ensure success at each stage of the process. Most of them also participated in the writers' workshop that helped to refine the revised Policy.

We also thank UNFPA, USAID and DFID for their financial and technical support to the review process.

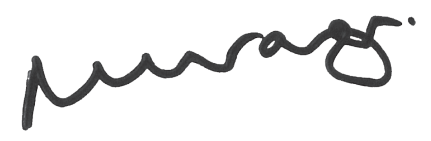

Dr. Nicholas Muraguri

Director, Medical Services Ministry of Health 


\section{FOREWORD}

According to the Kenya Population Situation Analysis (2013), the country has a rapidly growing population with the majority (24\%) being below 20 years. This young population has implications on the social, economic and political agenda of the country. A young population puts great demands on provision of health services, education, water and sanitation, housing and employment. At the same time, it provides opportunities for the country's development if the adolescents get opportunities to attain educational goals and receive an all round preparation for responsible adulthood. This segment of the population, therefore, requires close attention of all sectors of government, development partners and other stakeholders for the country to attain the Vision 2030', African Youth Charter (2006) and Post-2015 Development Agenda through Sustainable Development Goals (SDGs).

Kenya's first Adolescent and Reproductive Health and Development (ARHD) Policy was developed in 2003. Since then a lot of things have changed at the national and international levels that needed to be taken into account as the Policy was reviewed. This includes the Constitution of Kenya (2010) with its attendant devolved governance structure as well as demographics, social, economic and technological environment. The government has made concerted efforts as part of Vision 2030 to respond to adolescents and young people by providing opportunities for economic development and skills building. The dedication of a Directorate for Youth and the setting up of funds earmarked for youth entrepreneurships is commendable.

An ARHD Policy Implementation Assessment (2013) conducted by the National Council for Population and Development (NCPD) and the former Division of Reproductive Health (DRH), currently Reproductive and Maternal Health Services Unit, with technical and financial support from USAID through the Population Reference Bureau (PRB) revealed that the ARHD Policy improved the environment for implementation of ASRH programs and services in the country. The assessment also showed that the Policy laid the foundation for development of related policies, strategies and guidelines on ASRH as well as enhanced partnerships between government, private sector, non-governmental organizations (NGO) and civil society organizations (CSOs). In addition, it provided a platform for improvement of knowledge and attitudes towards Adolescent Sexual and Reproductive Health (ASRH) among adolescents, parents, teachers, religious leaders and community members and to some extent empowered adolescents to utilize available health services. 
However, the ARHD Policy faced various implementation challenges which include delayed development of the Plan of Action, inadequate dissemination of both the Policy and Plan of Action, lack of coordination among implementing partners, low stakeholder and youth involvement, limited leadership, inadequate resources, lack of political will and cultural and religious barriers to ASRH.

The foregoing necessitated review of the ARHD Policy. The National Adolescent Sexual and Reproductive Health Policy aims to enhance SRH status of adolescents in Kenya and contribute towards realization of their full potential in national development. The Policy intends to bring adolescent sexual and reproductive health and rights issues into the country's mainstream health and development agenda.

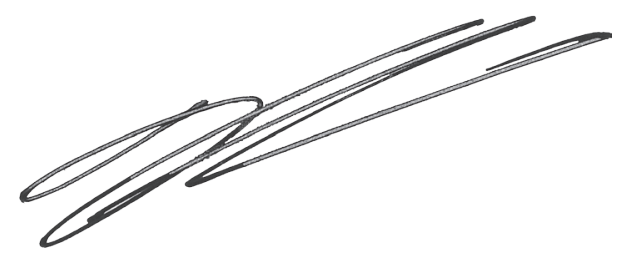

James Macharia

Cabinet Secretary, Ministry of Health 


\section{ACRONYMS}

$\begin{array}{ll}\text { AACSE } & \text { Age Appropriate Comprehensive Sexuality Education } \\ \text { AIDS } & \text { Acquired Immune Deficiency Syndrome } \\ \text { APHRC } & \text { African Population and Health Research Center } \\ \text { ARHD } & \text { Adolescent Reproductive Health and Development } \\ \text { ASFR } & \text { Age Specific Fertility Rate } \\ \text { ASRH } & \text { Adolescent Sexual and Reproductive Health } \\ \text { CBO } & \text { Community-Based Organization } \\ \text { CHMT } & \text { County Health Management Team } \\ \text { CSO } & \text { Civil Society Organization } \\ \text { NCAHU } & \text { Newborn, Child and Adolescent Health Unit } \\ \text { FBO } & \text { Faith-Based Organization } \\ \text { FGC/FGM } & \text { Female Genital Cutting/Female Genital Mutilation } \\ \text { GBV } & \text { Gender Based Violence } \\ \text { GER } & \text { Gross Enrolment Ratio } \\ \text { HIV } & \text { Human Immunodeficiency Virus } \\ \text { HMIS } & \text { Health Management Information System } \\ \text { HPV } & \text { Human Papillomavirus } \\ \text { ICC } & \text { Interagency Coordinating Committee } \\ \text { ICPD } & \text { International Conference on Population and Development } \\ \text { ICT } & \text { Information, Communication and Technology } \\ \text { IDEA } & \text { Informing Decision Makers to Act } \\ \text { JICC } & \text { Joint Interagency Coordinating Committee } \\ \text { KAIS } & \text { Kenya AIDS Indicator Survey } \\ \text { KDHS } & \text { Kenya Demographic and Health Survey } \\ \text { KEPH } & \text { Kenya Essential Package for Health } \\ \text { KHSSP } & \text { Kenya Health Sector Strategic and Investment Plan } \\ \text { KPHC } & \text { Kenya Population and Housing Census } \\ \text { KSPA } & \text { Kenya Service Provision Assessment } \\ \text { M\&E } & \text { Monitoring and Evaluation } \\ \text { MDGs } & \text { Millennium Development Goals } \\ & \end{array}$




$\begin{array}{ll}\text { MMR } & \text { Maternal Mortality Rate } \\ \text { MOEST } & \text { Ministry of Education Science and Technology } \\ \text { MOH } & \text { Ministry of Health } \\ \text { MSM } & \text { Men having Sex with Men } \\ \text { NACADA } & \text { National Authority for Campaign against Alcohol and } \\ & \text { Drug Abuse } \\ \text { NACC } & \text { National AIDS Control Council } \\ \text { NCPD } & \text { National Council for Population and Development } \\ \text { NER } & \text { Net Enrolment Rate } \\ \text { NGO } & \text { Non-Government Organization } \\ \text { RH } & \text { Reproductive Health } \\ \text { RH-ICC } & \text { Reproductive Health-Interagency Coordinating Committee } \\ \text { RMHSU } & \text { Reproductive and Maternal Health Services Unit } \\ \text { RHT\&S } & \text { Reproductive Health Training and Supervision } \\ \text { SCHMT } & \text { Sub-County Health Management Team } \\ \text { SGBV } & \text { Sexual and Gender-Based Violence } \\ \text { SRH } & \text { Sexual and Reproductive Health } \\ \text { SRHR } & \text { Sexual and Reproductive Health and Rights } \\ \text { STD/STI } & \text { Sexually Transmitted Disease/Infection } \\ \text { STEP UP } & \text { Strengthening Evidence for Programming on Unintended } \\ & \text { Pregnancy } \\ \text { TFR } & \text { Total Fertility Rate } \\ \text { TWG } & \text { Technical Working Group } \\ \text { UNICEF } & \text { United Nations Children's Fund } \\ \text { UNESCO } & \text { United Nations Educational, Scientific and Cultural } \\ \text { UNFPA } & \text { Organization } \\ \text { VMMC } & \text { Vnited Nations Population Fund } \\ \text { VVF } & \text { Vesico Vaginal Fistulae } \\ \text { WHO } & \text { World Health Organization } \\ & \end{array}$




\section{DEFINITION OF TERMS}

Abortion: The deliberate termination of a pregnancy, usually before the embryo or fetus is capable of independent life. In medical contexts, this procedure is called an induced abortion and is distinguished from a spontaneous abortion (miscarriage) or stillbirth. ${ }^{2}$

Adolescents: These are persons aged between 10 and 19 years. This shall be the working definition in the Policy.

Adolescent-Friendly Services: These are Sexual and Reproductive Health services delivered in ways that are responsive to specific needs, vulnerabilities and desires of adolescents. These services should be offered in a nonjudgmental and confidential way that fully respects human dignity.

Age Appropriate: This is suitability of information and services for people of a particular age, and in the case of the Policy, particularly in relation to adolescent development.

Age Appropriate Comprehensive Sexuality Education (AACSE): This is an age-appropriate, culturally relevant approach to teaching about sexuality and relationships by providing scientifically accurate, realistic and non-judgmental information. Sexuality education provides opportunities to explore one's own values and attitudes as well as build decision-making communication and risk reduction skills about many aspects of sexuality.

Child: This is an individual who has not attained the age of 18 years.

Child Abuse: Child maltreatment, sometimes referred to as child abuse and neglect, includes all forms of physical and emotional ill-treatment, sexual abuse, neglect and exploitation that results in actual or potential harm to the child's health, development or dignity. Within this broad definition, five sub-types can be distinguished - physical abuse, sexual abuse, neglect and negligent treatment, emotional abuse and exploitation. ${ }^{3}$

Child Marriage: This is a situation where marriage, cohabitation or any arrangement is made for such marriage or cohabitation with someone below the age of 18 years. 
Female Genital Mutilation (FGM): Comprises all procedures involving partial or total removal of the female genitalia or any other injury to the female genital organs or any harmful procedure to the female genitalia, for nonmedical reasons and includes clitoridectomy, excision and infibulations but does not include a sexual reassignment or a medical procedure that has a genuine therapeutic purpose.

Gross Enrolment Ratio (GER): Total enrolment in a specific level of education, regardless of age, expressed as percentage of the eligible official school age population corresponding to the same level of education in a given school year. ${ }^{4}$

Health: A state of complete physical, mental and social well-being and not merely the absence of disease or infirmity. ${ }^{5}$

Life Skills Education: This is a structured program of needs and outcomes based participatory learning that aims to increase positive and adaptive behavior by assisting individuals to develop and practice psycho-social skills that minimize risk factors and maximize protective factors. Life skills education programs are theory and evidence based, learner-focused, delivered by competent facilitators and are appropriately evaluated to ensure continuous improvement of documented results. ${ }^{6}$

Marginalized and Vulnerable Adolescents: These are adolescents at high risk of lacking adequate care and protection. For the purpose of the Policy, the term includes orphans and street children as well as adolescents with disabilities; adolescents living with HIV and AIDS; adolescents living informal settlements; adolescents in the labor market; adolescents who are sexually exploited; adolescents living below poverty line and children affected by disaster, civil unrest or war as well as those living as refugees.

Non-State Actors: A non-state actor is as an entity that is not part of any state or a public institution. Non-state actors range from grassroots community organizations to non-governmental organizations, philanthropic foundations and academic institutions.?

Net Enrolment Rate (NER): Refers to enrolment of the official age group for a given level of education expressed as a percentage of the corresponding population. ${ }^{8}$

Orphan: A child below 18 years of age whose mother (maternal orphans) or father (paternal orphans) or both (double orphans) are dead. 
Persons With Disability: Any person with physical, sensory, mental, psychological or any other impairment, condition or illness that has, or is perceived by significant sectors of the community to have a substantial or long term effect on their ability to carry out ordinary day-to-day activities.

Post-Abortal Care: Is the physical (medical), social and psychological care and support given to a person after an abortion

Reproductive Health: This is a state of complete physical, mental and social well-being, and not merely the absence of disease or infirmity, in all matters relating to the reproductive system, its functions and processes.

Sexual, Reproductive Health and Rights: The exercise of control over one's sexual and reproductive health linked to human rights and includes the right to:

- Reproductive health as a component of overall health, throughout life cycle, for both men and women;

- Reproductive health decision-making, including voluntary choice in marriage, family formation, determination of the number, timing and spacing of one's children, right to access information and means needed to exercise voluntary choice;

- Equality and equity for men and women, to enable individuals to make free and informed choices in all spheres of life, free from discrimination based on gender; and

- Sexual and reproductive health security, including freedom from sexual violence and coercion, and the right to privacy.

Sexual Health: A state of physical, emotional, mental and social well-being in relation to sexuality; it is not merely the absence of disease, dysfunction or infirmity. Sexual health requires a positive and respectful approach to sexuality and sexual relationships, as well as the possibility of having pleasurable and safe sexual experiences, free of coercion, discrimination and violence. For sexual health to be attained and maintained, the sexual rights of all persons must be respected, protected and fulfilled.

Sexual Offence: This includes defilement, rape, incest, sodomy, bestiality and any other offence prescribed in the Sexual Offences Act (2006).

Sexuality: It is a central aspect of being human throughout life and encompasses sex, gender identities and roles, sexual orientation, eroticism, pleasure, intimacy and reproduction. Sexuality is experienced and expressed in thoughts, fantasies, desires, beliefs, attitudes, values, behaviors, practices, 
roles and relationships. While sexuality can include all of these dimensions, not all of them are always experienced or expressed. Sexuality is influenced by the interaction of biological, psychological, social, economic, political, cultural, legal, historical, religious and spiritual factors.

State Actors: These include government ministries, departments and agencies.

Trafficking in Persons: This is the recruitment, transportation, transfer, harboring or receipt of persons by means of threat, use of force or other forms of coercion, abduction, fraud, deception, abuse of power or a position of vulnerability, giving or receiving of payments or benefits to achieve the consent of a person having control over another person, for the purpose of exploitation ${ }^{9}$ and any other offense prescribed in the Counter Trafficking in Persons Act (2010).

Unsafe Abortion: A procedure for terminating pregnancy performed by persons lacking the necessary skills or in an environment that is not in conformity with minimal medical standards or both. 


\section{PREAMBLE}

According to the 2009 Kenya Population and Housing Census (KPHC), adolescents aged 10-19 years constitute about 24 percent of the country's total population (9.2 million). In Kenya, as in other parts of Sub-Saharan Africa, adolescents face severe challenges to their lives and general well-being. They are vulnerable to early and unintended pregnancy, unsafe abortion, female genital mutilation (FGM), child marriages, sexual violence, malnutrition and reproductive tract infections including sexually transmitted infections (STIs) as well as HIV and AIDS.

\subsection{Policy and Legal Context}

Kenya's commitment to addressing the issues affecting adolescents is demonstrated by the fact that the country is a signatory to several international and regional human rights treaties and declarations.

These include the Ministerial Commitment on Comprehensive Sexuality Education and SRH Services for Adolescents and Young People in Eastern and Southern Africa (ESA, 2013), Convention on the Rights of the Child (CRC) ratified in 1990, Program of Action of the International Conference on Population and Development (ICPD, 1994) and the MDGs approved by the World Summit on Sustainable Development in September, 2000 as well as the Maputo Plan of Action 2007-2010.

Nationally, Sexual Reproductive Health (SRH) issues are addressed within various legislative and policy frameworks. These include the Constitution of Kenya (2010), Sexual Offences Act (2006), Children's Act (2001), Counter Trafficking in Persons Act (2010), Prohibition of FGM Act (2011), Person With Disability Act (2003), HIV and AIDS Prevention and Control Act (2006), Marriage Act (2014), National Reproductive Health Policy (2007), National Youth Policy (2007), Sessional Paper No. 3 on Population Policy for National Development (2012), Gender Policy in Education (2007), Kenya Health Policy (2012-2030), Kenya Health Sector Strategic and Investment Plan (2013-2017), Education Sector Policy on HIV and AIDS (2013), National School Health Policy (2009), National Gender-Based Violence (2014) and Kenya Vision 2030.

From the information above, Kenya has a favorable policy and legal context. However, there is need to address other aspects that have a bearing on the health of young people. Income and social status are linked to living conditions 
(physical environment) that include aspects such as safe water and clean air among others. Other factors are social support systems, individual make up and gender related factors (male and female adolescents and young people suffer from different conditions at different ages).

Though many of these factors are beyond their control and often lead to poor health outcomes, they are more critical than access and use of health care. Age of consent (above 18 years) and education efforts to keep girls in school and help for those who get pregnant in school to go back to and complete secondary education play a key role in the health of adolescents and young people. Poor education is associated with stress as well as low self-confidence and ultimately poor choices.

\subsection{Rationale for Revision}

Adolescents comprise about 24 percent of Kenya's population ${ }^{10}$. This large adolescent population has implications on the country's health and development agenda as it is likely to put increasing demands on provision of services. Adolescents require priority attention from all sectors of government and development partners for the country to be able to realize its Medium Term Plan (2013-2017), Vision 2030, MDGs and Post-2015 Development Agenda.

The ASRH Policy will provide guidance to government ministries and development partners working with the Ministry of Health on how to respond to adolescents $\mathrm{SRH}$ needs. Responding to the multifaceted changes of Adolescent Sexual and Reproductive Health requires a clear understanding of their circumstances and issues. There is also need for an integrated approach that is not just problem-oriented but one that provides for mitigation of risk factors and puts in place a safety net for early detection and prevention of $\mathrm{SRH}$ challenges.

Since development of the first Adolescent Reproductive Health and Development Policy (ARHD) in 2003, the international, regional and national legislative and policy landscape has changed with regard to adolescents. Many continuing and emerging issues have come to the fore as a result of advances in information, communication and technology (ICT) and the resultant exposure to materials and practices that influence young people's behavior. These issues include: high incidence of poverty; early initiation of sex by adolescents; increased Human Immunodeficiency Virus (HIV) incidence and prevalence as well as AIDS-related deaths among adolescents; adolescents affected by HIV; Human Papillomavirus (HPV); drugs and substance use; harmful traditional 
practices that impact negatively on adolescent health and future well-being; and $\mathrm{SRH}$ needs of adolescents with disabilities together with increased ease of access to varied ICT channels among adolescents. These factors together with changing adolescent needs have necessitated revision of the Policy.

This revision has also been informed by insights gained on Adolescent Sexual and Reproductive Health (ASRH) from the Kenya Population and Housing Census (KPHC) 2009, Kenya Demographic and Health Survey (KDHS) 2014, Kenya Service Provision Assessment (KSPA) 2010, Adolescent and Youth Reproductive and Sexual Health: Taking Stock in Kenya (2011), Adolescent and Youth Sexual and Reproductive Health Evidence-Based Interventions (2013), Insights on Family Health in Kenya (2013), Kenya Adolescent Reproductive Health and Development Policy: Implementation Assessment Report (2013), Global Evaluation of Life Skills (2012) and Kenya Population Situational Analysis (2013). Others include international declarations and conventions on young people's sexual and reproductive health.

The lessons learnt in the process of the review include working with ministries of Education and Health among other line ministries and is critical for inclusion and participation of young people. Political will and involvement of stakeholders at different levels made the exercise inclusive. For instance, under the devolved governance, reproductive health coordinators gave their input thus reaching more ASRH players. In addition, the need for segregated data rather than putting together adult and children's data in the Health Management Information System (HMIS) was noted. It was noted that lumping the data together makes it difficult to utilize it for programming and decision making.

\subsection{National Adolescent Sexual and Reproductive Health Policy}

The aim of the ASRH Policy, therefore, is to enhance the SRH status of adolescents in Kenya and contribute towards realization of their full potential in national development. The Policy intends to bring Adolescent Sexual and Reproductive Health and Rights issues into the mainstream of health and development. The Policy examines the prevailing social, economic, cultural and demographic context of sexual and reproductive health of adolescents including its implications for and consequences to their health and development. As a complement to sector-specific policies and programs, the Policy defines structures and key components of ASRH to facilitate their mainstreaming in all sectoral planning activities. 
In addition, the Policy has outlined principles, objectives, priority areas and actions for ASRH in Kenya. The management and coordination, provision of ASRH services, roles and responsibilities of various sectors and stakeholders, research and utilization of evidence-based interventions as well as monitoring and evaluation are spelt out in the policy implementation framework section.

The focus of National Adolescent Sexual and Reproductive Health Policy is health rather than development. This is to enable a more directed focus on young people's Sexual and Reproductive Health. 


\section{PRINCIPLES}

The implementation of the Policy shall be guided by the following principles:

a. Respect for human rights and fundamental freedoms including the right to life, human dignity, equality and freedom from discrimination on the basis of gender, sex, age, disability, health status, geographical location or social, cultural and religious beliefs and practices.

b. Responsiveness to varying Sexual and Reproductive Health needs of adolescents in provision of care.

c. Provision of holistic and integrated ASRH information and services through multi-pronged and multi-sectoral approaches that are effective and efficient in reaching adolescents with information and services.

d. Recognition of the critical role parents, guardians and communities play in the promotion of SRH of adolescents.

e. Involvement of adolescents in the planning, implementation, monitoring and evaluation of ASRH programs for effective program implementation, promotion of partnerships and creation of open channels of communication for achievement of mutual goals.

f. Utilization of evidence-based interventions and programming. 


\section{SEXUAL AND REPRODUCTIVE HEALTH STATUS OF ADOLESCENTS IN KENYA}

According to the World Health Organization (WHO), an adolescent is any person between the age of 10 and 19 years. Adolescence is a period marked by significant growth, remarkable development and changes in the life course for boys and girls, filled with vulnerabilities and risks, as well as incredible opportunities and potential. The experiences of adolescents shape the direction of their lives and that of their families. Therefore, paying attention to adolescents' health and education is a life-time investment that is likely to have positive effects on behavior and lifestyle during the entire course of their life."1

Sexual Debut, Contraception and Fertility: According to the Kenya Demographic and Health Survey (KDHS) 2008-2009, the median age at first sexual intercourse in Kenya was 18.2 years for women and 17.6 years for men. Though the median age at first sexual intercourse has been increasing (from 16 in 1993 to 18 in 2008-2009), about 12 percent of girls and 22 percent of boys reported to have had sex by the age of $15.12,13$ Similarly, 37 percent of girls and 44 percent of boys aged 15 to 19 years have had sex. Among married adolescent women aged 15-19, 40 percent were currently using any method of contraception and 37 percent were using a modern method. Notably, contraceptive use among adolescents varies by region, residence, education, household wealth and marital status. ${ }^{12}$ One in three adolescent married girls (30\%) had an unmet need for family planning. ${ }^{12,13}$

The Age Specific Fertility Rate (ASFR) for women in Kenya aged 15-19 is 96 births per 1,000 women ${ }^{14}$ and most recently it is estimated to have increased to 121 births per 1,000 women. ${ }^{15}$ Since 1975, the contribution of these age groups to the national Total Fertility Rate (TFR) has increased from 32 percent to 37 percent in 2008.16 Even though the ASFR for adolescents has declined over the years, the contribution of a large pool of young women to total fertility rate is significant and increasing because of their absolute numbers, early child bearing and marriage at a young age. ${ }^{12}$ Approximately 18 percent of adolescents (15-19 years) had begun childbearing, ranging from 10 percent among girls with secondary education to 32 percent among girls with no education. ${ }^{14}$ Among women aged $20-24$, one out of four (26\%) had begun childbearing by age $18 .^{12}$ 
A number of factors have been associated with adolescent pregnancies. While many adolescents may choose to get pregnant, many pregnancies occur in the context of human rights violations such as child marriage, coerced sex or sexual abuse. ${ }^{16}$ Broader socio-economic factors such as poverty, lack of education and limited economic opportunities among girls may also contribute to adolescent pregnancy rates. Furthermore, lack of reproductive healthcare services for adolescents particularly a lack of contraceptive education and affordable, available contraceptive commodities means contraceptive use among married and unmarried adolescents is generally low in developing regions. ${ }^{18}$

Adolescents face greater adverse complications during pregnancy because they are not fully physiologically and biologically prepared for pregnancy due to among other factors gynecological immaturity and incomplete pelvic growth. Other underlying factors include smoking, substance abuse, anemia, malaria, HIV and AIDS as well as other sexually transmitted infections. ${ }^{19}$

Adolescents may be disadvantaged in maintaining a healthy pregnancy due to poor health education, inadequate access to antenatal care and skilled birth attendance among other healthcare services, or the inability to afford costs of pregnancy and childbirth. Adolescent pregnancy, whether intended or unintended, increases the risk of maternal mortality and morbidities including complications of unsafe abortion, prolonged labor, delivery and post-natal period.

Country-specific adolescent mortality data are not available. However, estimates from developing countries indicate that pregnancy and delivery complications, including unsafe abortion, are the second leading causes of death for girls below 20 years. ${ }^{19}$ A recent study conducted on the incidence and magnitude of abortions showed that girls below the age of 19 accounted for 17 percent of all women seeking post-abortion care services and about 45 percent of all severe abortion-related admissions in Kenyan hospitals in 2012. ${ }^{21}$

In addition to physiological immaturity, delay in receiving medical attention or emergency obstetric care at a health facility contributes to high rates of obstetric fistula among adolescents. An assessment by UNFPA on obstetric fistula showed there was a lack of accurate prevalence data in Kenya. However, studies in Africa indicate that 58 percent to 80 percent of women with obstetric fistula are under the age of 20.22 According to KDHS 2008-2009, nearly half (47\%) of pregnancies among adolescents were unintended and less than half of girls aged below 20 reported that they delivered in a public or private health facility or with the help of a skilled birth attendant. 
Consequences of unintended pregnancy among girls in Kenya include termination of education (dropping out of school), child marriage and unsafe abortion. Evidence from KDHS 2008-2009 shows that among adolescent girls who had started childbearing by age 18 in Kenya, 98 percent were out of school, indicating that early pregnancy clearly means the end of education for almost all adolescent girls. It is estimated that about 13,000 girls drop out of school annually in Kenya due to early and unintended pregnancy. ${ }^{23}$

There is also evidence of association between adolescence and adverse neonatal outcomes such as infant mortality, preterm birth, low birth weight and malformations among adolescent mothers. ${ }^{24}$ There is higher maternal mortality rates at 260 per 100,000 among younger adolescents (15-19 years) compared to 190 per 100,000 among older adolescents (20-24 years). ${ }^{25}$

HIV and AIDS and STIS: HIV prevalence has decreased significantly among young people aged 15 to 19 years, declining from about 3.0 percent in 2003 to 1.1 percent in 2012. The HIV prevalence rate for adolescents aged 15-19 was almost similar for young women (1.1\%) and young men (0.9\%), while adolescents living in urban areas had higher HIV prevalence rates (2.2\%) compared to their rural counterparts (0.5\%). For those who reported first sex before 15 years, HIV prevalence was 5.3 percent among young women and 0.3 percent among young men. ${ }^{26}$ Key populations ${ }^{a}$ of adolescents such as men who have sex with men, injecting drug users and sex workers are at an increased risk of HIV infection. An estimated 20-40 percent of female sex workers began commercial sex work before the age of 18 and a recent study in Kenya found a baseline HIV prevalence of 40 percent among young MSM who sell sex in Nairobi. ${ }^{27}$

Overall, adolescents between the ages of 10 and 19 years represented about nine percent of persons living with HIV and 13 percent of all HIV-related deaths in Kenya. It is reported that HIV testing rates for Kenya are lowest among adolescents between 15-19 years (49.8\%), with only 23.5 percent reporting awareness of their status. ${ }^{27}$ Forty-nine percent of young women aged 15-19 and 60 percent of those aged 20-24 had comprehensive knowledge of HIV while 58 percent of young men aged 15-19 and 71 percent of those aged 2024 had comprehensive knowledge of HIV; 53 percent of female adolescents and 34 percent of their male counterparts reported condom use during their sexual debut compared to 70 percent of females and 65 percent of males aged 15 and above ${ }^{26}$. Among never-married adolescents, girls were less likely to have used a condom during their last sexual encounter (42\%) compared to their male counterparts (55\%). 
Sexually transmitted infections (STIS), especially those that are ulcerative, are associated with an increased risk of HIV infection and have significant implications for reproductive health outcomes. ${ }^{28,29}$ Among Kenyan adolescents aged 15-19, only one percent of girls and 0.3 percent of boys self-reported an STI. Among those aged 20-24, 1.9 percent of girls and 1.9 percent of boys selfreported an STI. ${ }^{12}$ However, these estimates are likely to be underreported due to lack of knowledge of common symptoms of these conditions as well as routine clinical monitoring of STIs especially among young people. ${ }^{23}$

Sexual Abuse and Violence: According to a national study by UNICEF (2012) on violence against children in Kenya, adolescent girls aged 13-17 were more likely to have experienced sexual violence in the previous 12 months (10.7\%) compared with similar age group of boys (4.2\%). ${ }^{30}$ In addition, nearly half of both adolescent girls and boys reported experiencing physical violence in the 12 months preceding the survey. ${ }^{14}$ Adolescents who suffer sexual abuse are more likely to be exposed to unintended pregnancy, unsafe abortion and STIs including HIV. 31,32

Drug and Substance Abuse remains one of the major problems confronting young people in Kenya today. Studies indicate that many in- and out-of-school adolescents, street children and other groups of adolescents use and abuse drugs and alcohol. ${ }^{33,34}$ According to a 2012 rapid assessment of drugs and substance use in Kenya, about 18 percent of adolescents aged 15-17 reported ever using any drug or substance, including tobacco, Khat (Miraa), narcotics and inhalants. ${ }^{35}$ Specifically, about two percent of females and four percent of males aged 10-14 and about 11 percent of 15-17 year olds reported ever using alcohol. Despite the need for services to address substance abuse, very few drug rehabilitation programs and counseling centers are available for adolescents in Kenya and these tend to be urban-based. ${ }^{12}$ For adolescents, substance use and abuse is associated with increased risk for early sexual debut, multiple sexual partners and early childbearing. ${ }^{36}$

Harmful Practices: A number of social and cultural practices, some rooted in traditional attitudes and others evolving around modern times, have a direct impact on reproductive health activities and status of adolescents and young people. Among those of most urgent concern to the Policy are Female Genital Mutilation (FGM), sexual abuse and violence, drug and substance abuse as well as child marriage. 
a. Female Genital Mutilation (FGM) is a deeply rooted cultural practice that remains prevalent in Kenya despite being outlawed in 2001 by the Children's Act and Prohibition of FGM Act 2011, and being a violation of rights. ${ }^{37}$ Female Genital Mutilation is associated with immediate and long term social, physical, psychological and health consequence. ${ }^{38}$ Among young girls aged 15-19, FGM declined from 15 percent in 2008 to 11 percent in 2014.12, 16, 39 These levels are still quite high considering the numerous adverse consequences of FGM and that in some communities the practice is nearly universal, for example, the North Eastern region (98\%). In addition, girls who have undergone FGM as a rite of passage are likely to drop out of school, experience child marriage and early child bearing.

b. Child marriage: According to KDHS 2008-2009, six percent of females were married by age 15 and 26 percent by age 18. Estimates of child marriage in Kenya generally vary by place of residence and region, with higher prevalence in rural areas (31\%) relative to urban areas (16\%). It is highest in North Eastern (56\%) and Coast (41\%); and lowest in Nairobi (7\%). ${ }^{40}$ Child marriage is associated with termination of education (dropping out of school), low labor force participation, increased risk of HIV infection, heightened risk of gender-based violence (GBV), early childbearing as well as high fertility rates. There is also a risk of high infant mortality as well as maternal morbidity and mortality. ${ }^{41}$

\section{Marginalized and Vulnerable Adolescents}

a. Adolescents living in informal settlements: The National Housing and Population Census (2009) Report indicates that 31 percent of the Kenyan population lives in urban centers. The intercensal urban growth rate was 8.3 percent between 1999 and 2009 with the highest growth being experienced in the three major cities - Nairobi, Mombasa and Kisumu. The rapid growth of urban centers has resulted in the mushrooming of informal settlements as people look for better opportunities. Informal settlements (also referred to as slums), because of heightened poverty and limited opportunities, expose young people to risky sexual behaviors including early sexual debut, low contraceptive use, transactional sex, sexual coercion/abuse, high burden of unintended pregnancies, and drug and alcohol abuse. ${ }^{42}$ For example, recent studies in Nairobi slums show that about 11 percent of males and nine percent of females had initiated sexual activity before the age of 15, with 84 percent of females and 87 percent of males already sexually active by age $20 .{ }^{43}$ 
b. Adolescents in the labor market: Child labor is internationally considered work undertaken by children between the ages of five and 17 years that prevents them from attending school, is exploitative, hazardous or inappropriate for their age. ${ }^{44}$ In the International Labor Convention No. 182, the worst forms of child labor are defined as trafficking, prostitution, pornography, recruitment of children for armed conflicts and use of children for illicit activities. ${ }^{45}$ In Kenya, the law recognizes the age of employment as 16 years and above (GoK Employment Act, 2007). According to the Kenya Integrated Household and Budget Survey 2005-2006, approximately one million children aged between five and 17 years were working. ${ }^{44}$ More than half of the working children were boys (53\%) and the majority (90\%) were found in rural areas. Of the working children, approximately 77 percent $(774,000)$ were considered child laborers. ${ }^{44}$ Due to low educational attainment, child labor is associated with limited access to reproductive health information and services as well as opportunities for self-advancement.

c. Adolescents with disabilities: The declaration of an African Decade of Persons with Disabilities (1999-2009) recognizes that disability severely affects chances of gaining an education. In addition people with disabilities cannot easily access health services, and this has implications on their sexual and reproductive health. The prevalence of disability among adolescents 10-19 years in Kenya is estimated at about four percent with one out six reporting their first pregnancy by age 20.46 While in Kenya data is not available specifically for adolescents with disability, estimates for youth (15-24 years) show that about 87 percent were married or in a relationship but only 12 percent were using a modern contraceptive method. ${ }^{47}$

d. Adolescents living with HIV: Adolescents living with HIV face unique challenges as they transition to adulthood because they are less likely to be in school, likely to be orphaned, lack appropriate services and are often unable to negotiate contraceptive use or even access contraceptive methods. ${ }^{48}$ Of the approximately 1.6 million Kenyans living with HIV in 2013, about 16 percent were children and adolescents (0-19 years). ${ }^{49,50}$ About half of adolescents (15-19 years) had ever been tested and only a quarter of those knew their HIV status (24\%). Among sexually active HIV positive adolescents, only a quarter reported using condoms at their first sexual intercourse. In a study conducted in 2011 in Rift Valley and Coast regions among HIV positive adolescents (15-19 years), 76 percent of boys and girls intended to have children in future, 
two-thirds of HIV positive girls had already begun childbearing or were pregnant, while 27 percent of boys had impregnated someone. In addition, 75 percent of pregnancies among HIV positive girls were reported as unintended. Moreover, 64 percent of girls and 48 percent of boys were out of school. ${ }^{51}$

e. Married adolescents: Married adolescents experience sexual intercourse more frequently compared with girls who are not married, with very limited condom use despite a higher risk of HIV..$^{23,52,53}$ Evidence suggests that the age gap between married adolescents and their partners tends to be large, while marriage to peers is often a coping mechanism usually in the context of an unintended pregnancy. ${ }^{53,54}$ Partly due to limited education, married adolescents have less access to SRH information and services, while power imbalance within relationships increases their odds to intimate partner violence. ${ }^{56,57}$

f. Orphaned adolescents: According to KAIS 2012, there are about 1.8 million orphans aged zero to 17 years in Kenya, with a higher proportion among 10 to 17 year olds (66\%). Estimates range from about 30 percent in Nyanza to about four percent in Nairobi. Nearly half of the estimated number of orphans in Kenya is as a result of the HIV and AIDS epidemic. This epidemic has also contributed to the increased number of adolescents heading or living in child-headed households, a particularly vulnerable group of orphaned adolescents. Orphans tend to lack guidance and support which is associated with increased vulnerability to risky behaviors among children. ${ }^{58}$

g. Adolescents in humanitarian/emergency situations: In 2012, the number of internally displaced persons (IDPs) in Kenya was estimated at between 250,000 and 300,000 people. ${ }^{59}$ Kenya also hosts one of the largest refugee populations in Sub-Saharan Africa, with an estimated 580,111 registered refugees and asylum seekers resident in the country. ${ }^{60}$ Evidence shows that displaced women face particularly high levels of maternal mortality, unmet need for family planning, complications following unsafe abortion and increased gender-based violence as well as sexually transmitted infections, including HIV. ${ }^{61}$ Public health care systems are often unprepared to meet the needs of these populations and particularly their SRH needs. ${ }^{56,61}$ In addition, there are usually no services designed to meet SRH needs of adolescents in these populations. ${ }^{59}$ 


\section{ASRH POLICY FRAMEWORK}

\subsection{ASRH Policy Goal, Objectives, Priority Areas and Actions}

\subsubsection{Goal}

The goal of the Policy is to enhance the Sexual Reproductive Health status of adolescents in Kenya and contribute towards realization of their full potential in national development.

\subsubsection{Broad Objectives}

The broad objectives of the Policy are to:

1. Promote an enabling legal and socio-cultural environment for provision of SRH information and services for adolescents;

2. Enhance equitable access to high quality, efficient and effective adolescent friendly ASRH information and services;

3. Increase gender equity and equality in SRH amongst adolescents;

4. Strengthen inter-sectoral coordination and networking, partnership and community participation in adolescent SRH;

5. Support adolescent participation and leadership in SRH planning and programming at all levels; and

6. Strengthen collection, analysis, and utilization of age and sex disaggregated data on adolescents.

\subsubsection{Specific Objectives}

The Policy, therefore, identifies the following specific objectives:

1. Promote adolescent sexual reproductive health and rights;

2. Contribute to increased access to ASRH information and age appropriate comprehensive sexuality education (AACSE);

3. Contribute to reduction of STIs burden, including HPV and HIV as well as improvement of appropriate response for infected adolescents;

4. Reduce early and unintended pregnancies;

5. Reduction of harmful traditional practices;

6. Reduce drug and substance abuse;

7. Reduce Sexual and Gender-Based Violence (SGBV) incidences amongst adolescents to improve response; and

8. Address the special SRHR-related needs of marginalized and vulnerable adolescents. 


\subsubsection{Priority Areas and Actions}

To address the specific objectives, a series of priority actions have been identified as outlined below:

\subsubsection{Promote Adolescent Sexual and Reproductive Health and Rights}

The Policy shall:

1. Protect adolescents' Sexual Reproductive Health and Rights, and ensure attainment of these rights;

2. Promote adolescent participation in key decision making around policy, advocacy, budgeting, planning, research and implementation processes;

3. Promote education of parents and the community on Sexual and Reproductive Health and Rights of adolescents;

4. Mainstream gender and address its concerns in all ASRH programs;

5. Advocate for multi-sectoral and multi-pronged approaches to addressing SRHR issues among adolescents;

6. Strengthen capacities of institutions, service providers and communities to provide appropriate information and services to adolescents who require them; and

7. Support prioritization and allocation of resources to ASRH.

\subsubsection{Increase Access to ASRH Information and Age Appropriate Comprehensive}

\section{Sexuality Education}

The Policy shall:

1. Strengthen ASRH information and AACSE programs for out-of-school and in-school adolescents;

2. Support the provision of age-appropriate ASRH information;

3. Facilitate innovative approaches including utilization of digital platforms to enhance access to SRH information;

4. Build the capacity of health care providers to provide SRH information to adolescents;

5. Leverage on existing community health structures to provide ASRH information and AACSE;

6. Enhance the linkage between government ministries in charge of education and health (MoEST and $\mathrm{MoH}$ ); and

7. Promote appropriate costing and earmarking of programs targeting adolescents in national and county budgets. 


\subsubsection{Reduce STIs including HPV and HIV}

The Policy shall:

1. Support provision of accurate information on HIV and AIDS as well as other STIs to adolescents for risk reduction and ART adherence;

2. Promote screening and treatment of reproductive tract infections including STIS;

3. Promote HIV testing and counseling among adolescents including information on the potential benefits and risks of disclosure of their HIV status to others;

4. Promote scaling up of Voluntary Medical Male Circumcision (VMMC) targeting in- and out-of school adolescent boys;

5. Promote and scale up implementation of HPV vaccine programs for adolescents;

6. Promote generation of adolescent-specific disaggregated data and its utilization for decision making;

7. Support development of guidelines in conducting HIV and STI research among adolescents;

8. Establish and promote adolescent-friendly HIV counseling and testing sites including linkage with other services;

9. Ensure adequate capacity of healthcare workers at all levels of healthcare for the provision of integrated, high quality $\mathrm{SRH}$ services in the context of STIs and HIV to adolescents;

10. Support meaningful participation of adolescents throughout HIV programming cycle.

11. Enhance integration of HIV and AIDS among other STIs information and services into SRH services at all levels of health care;

12. Facilitate revision, where appropriate, of age and sex related restrictions that prevent adolescents from accessing full HIV and SRH services; and

13. Support community-based approaches to improve treatment adherence and retention in care of adolescents living with HIV.

\subsubsection{Reduce Early and Unintended Pregnancy}

The Policy shall:

1. Promote provision of accurate information and services to prevent early and unintended pregnancies among adolescents;

2. Enhance existing service provision channels to provide accurate information and services on a wide range of contraceptive methods to capture diverse needs of adolescents;

3. Ensure all pregnant adolescents, including the poor and 'hard-toreach', have access to skilled care throughout pregnancy, delivery and postnatal periods;

4. Enhance establishment of linkages for effective referrals to relevant services for pregnant adolescents; 
5. Strengthen programs to delay sexual debut and promote abstinence among adolescents;

6. Support review of all maternal and perinatal deaths and provide adolescent-specific maternal death reports;

7. Promote male involvement in prevention of early and unintended pregnancy;

8. Enhance provision of high quality post-abortal care services to adolescents;

9. Support sensitization and implementation of the Education Re-entry Policy and a social support system for adolescents;

10. Strengthen community involvement in prevention of early and unintended pregnancy;

11. Encourage political leaders, planners and community leaders to enforce laws and policies to prohibit marriage of girls below 18 years;

12. Support interventions to delay marriage of girls until they attain 18 years by influencing family and community norms; and

13. Promote educational opportunities for girls through formal and nonformal channels to delay marriage until they attain 18 years; and

14. Strengthen and scale up social protection for vulnerable adolescent girls to delay sexual debut as well as improve mental health and educational outcomes.

\subsubsection{Reduce Harmful Traditional Practices}

The Policy shall:

1. Strengthen capacities of institutions, communities, families and individuals to prevent and respond to harmful traditional practices to adolescents;

2. Encourage male involvement in prevention of harmful traditional practices;

3. Ensure monitoring and evaluation of interventions that are geared towards prevention, response and mitigation of traditional practices;

4. Support management of health consequences of harmful traditional practices;

5. Support implementation of appropriate policies and programs, as well as enforcement of legislation to reduce prevalence of harmful traditional practices;

6. Support sensitization of communities on existing legislation and policies that protect adolescents from harmful traditional practices;

7. Support programs and research on harmful traditional practices and promote appropriate evidence-based interventions; and

8. Support sensitization of reintegration to school of adolescents in early marriage and FGM situations. 


\subsubsection{Drug and Substance Abuse}

The Policy shall:

1. Promote provision of accurate information on dangers of drug and substance abuse among adolescents through in- and out-of-school programs;

2. Support provision of medical, legal and psychological services at all levels, including rehabilitation for adolescents exposed to drug and substance abuse;

3. Strengthen involvement of adolescents, families and communities in the prevention of drug and substance abuse among adolescents;

4. Encourage re-admission into school of adolescents after rehabilitation;

5. Support enforcement of relevant legislation on drug, alcohol and other substance abuse amongst adolescents; and

6. Establish multi-sectoral linkages particularly with NACADA for prevention and control of drug and substance abuse.

\subsubsection{Reduce Sexual and Gender-Based Violence (SGBV) and Improve Response}

The Policy shall:

1. Promote awareness among adolescents, family and communities about existing SGBV response services;

2. Promote male involvement in prevention of SGBV;

3. Strengthen provision of medical, legal and psychosocial support for adolescent survivors of SGBV;

4. Strengthen capacity of multiple stakeholders involved in prevention, response and management of SGBV;

5. Support advocacy for implementation of legal instruments that protect the rights of adolescents;

6. Enhance capacity of law enforcers and health service providers on prevention, response and mitigation of SGBV; and

7. Strengthen coordination of multi-sectoral and multi-pronged response to SGBV.

\subsubsection{Address SRHR needs of Marginalized and Vulnerable Adolescents}

The Policy shall:

1. Support provision of disability-friendly SRH information and services;

2. Support evidence generation and utilization of data on marginalized and vulnerable adolescents to guide ASRH programming;

3. Support linkages of SRH programs with livelihood opportunities for all marginalized and vulnerable adolescents; and

4. Ensure data collection tools capture adolescents with disabilities. 


\section{IMPLEMENTATION FRAMEWORK}

\subsection{Management and Coordination}

The National Adolescent Sexual and Reproductive Health (ASRH) Policy shall be implemented in line with existing national policies and strategies through a multi-sectoral approach that includes collaboration and partnerships with state and non-state actors including adolescents. It shall be managed and coordinated by the Ministry of Health $(\mathrm{MoH})$. At the County, Sub-County and Community levels, management and coordination shall be done by:

- County Health Management Teams (CHMT),

- County Hospital Management Teams,

- Sub-County Health Management Teams (SCHMT),

- Primary Care Facility Management Teams and

- Community Units.

Collaboration and partnerships shall be realized through the Joint Interagency Coordinating Committee (JICC); Health Sector Coordinating Committees (ICC and TWGs); County Health Stakeholders' Forum; Sub-County Health Stakeholders' Forum and Community Health Committees. The Policy encourages formation of TWGs at the county and sub-county levels.

\subsection{Provision of ASRH services}

The Policy shall ensure provision of SRH services for adolescents. It shall outline levels at which services shall be provided; applicable standards in service provision; and health system requirements for service provision.

\subsubsection{Levels of Service provision}

The Policy shall be implemented in a devolved health system across the following tiers:

- Tier 1 - Community Health Services

- Tier 2 - Primary Care Services

- Tier 3 - County Referral Services

- Tier 4 - National Referral Services

Facilities operated by NGOs, FBOs and private for-profit sector shall follow the same classification depending on their level of resources and capacity. The county governments shall be responsible for Tier 1, Tier 2 and Tier 3 services while the national government shall be responsible for Tier 4 . The referral system shall be strengthened to ensure that clients at all levels gain access to appropriate skilled care. 


\subsubsection{Standards for Provision of Adolescent-Friendly SRH Services}

Article 43 (1) of the Constitution of Kenya (2010) states that 'every person has the right to the highest attainable standard of health, which includes the right to health care services, including reproductive health care'.

The Policy shall support access to and provision of high quality and affordable adolescent-friendly SRH services at all levels of health service provision. The standards shall be described further in the national guidelines for adolescentfriendly SRH services.

\subsubsection{Health Systems Requirements}

A functional health system is a key determinant of quality of services. In order to provide efficient, effective and sustainable ASRH services, the following health system building blocks as outlined in the Kenya Health Sector Strategic and Investment Plan (2013-2017) are essential:

1. Health Financing and sustainability

2. Health Leadership

3. Health Products and Technologies

4. Health Information

5. Health Workforce

6. Service Delivery Systems

7. Health Infrastructure

\subsubsection{Health Financing and Sustainability}

The Policy recognizes the need to increase financial resources and to put in place sustainability mechanisms for effective and efficient provision of SRH services to adolescents. In this regard, the Ministry of Health shall:

a) Generate and avail evidence to justify resource allocation to ASRH programs;

b) Seek increased budgetary allocation for provision of ASRH information and services at national and county levels;

c) Coordinate and harmonize donor support for adolescent $\mathrm{SRH}$ programs;

d) Establish mechanisms for mobilizing financial resources, including Public Private Partnerships; and

e) Improve efficiency and accountability in resource allocation and utilization. 


\subsubsection{Health Leadership}

The Policy recognizes the role of leadership and governance in provision of Sexual and Reproductive Health services for adolescents. The Ministry of Health shall:

a) Build capacity of health managers at all levels in strategic leadership, health systems and service management for adolescents;

b) Strengthen Reproductive Health Training and Supervision (RHT\&S) system at all levels for effective provision of ASRH services;

c) Ensure that annual work plans at all levels of service provision prioritize adolescent SRH services;

d) Continuously monitor provision of adolescent $\mathrm{SRH}$ services at all levels; and

e) Establish and strengthen partnerships for adolescent SRH service provision at all levels.

\subsubsection{Health Products and Technologies}

Medical products, vaccines and technologies are essential in the provision of $\mathrm{SRH}$ services to adolescents. The Ministry of Health shall:

a) Ensure equitable access to essential medical products, vaccines and technology in health facilities at all levels;

b) Ensure linkage with other policies on the procurement system and commodity supply chain; and

c) Ensure linkage with institutions offering quality assurance of all medical $\mathrm{SRH}$ commodities used by adolescents.

\subsubsection{Health Information}

Health Management Information System (HMIS) is critical in the implementation of the Policy. Towards this end, the Ministry of Health shall take the following actions:

a) Revise and standardize data collection tools to capture age and sex disaggregated data for adolescents at all levels of data collection;

b) Strengthen HMIS for adolescents and establish linkages with the National Integrated Monitoring and Evaluation System (NIMES);

c) Routinely collect, analyze and utilize high quality data on adolescents for decision making at all levels; and

d) Utilize modern technology to improve management of ASRH information at all levels. 


\subsubsection{Health Workforce}

The Ministry of Health $(\mathrm{MoH})$ shall enhance human resources for provision of SRH services by:

a) Building capacity of health providers to provide adolescent-friendly $\mathrm{SRH}$ services through in service, on job training, mentorship and continuous medical education;

b) Supporting integration of ASRH training into pre-service curriculum in all medical training institutions; and

c) Strengthening quality assurance mechanisms through continuous support supervision and mentorship at all levels to provide adolescentfriendly SRH services.

\subsubsection{Service Delivery Systems}

The $\mathrm{MoH}$ shall ensure that $\mathrm{ASRH}$ services are delivered in ways that are responsive to specific needs, vulnerabilities and desires of adolescents in public, private and school health facilities. The services shall be offered in a non-judgmental and confidential way that fully respects human dignity. The following are some of the quality key components for health services to be considered adolescent-friendly:

- Effective

- Efficient

- Accessible

- Acceptable/patient-centered

- Equitable

- Safe

- Availability of age appropriate comprehensive SRH services

- Privacy and confidentiality

- Adolescent-friendly health care providers

- Adolescent involvement

- Community involvement

- Reliability and consistency

\subsubsection{Health Infrastructure}

The $\mathrm{MOH}$ health infrastructure will support the sexual and reproductive health service provision framework in order to manage the complex and emerging needs of adolescents and young people in general. Service-related issues to be addressed include: 
- Access

- Assessment of capacities

- Communication

- Effectiveness

- Efficiency

- Information systems for data collection

- Patient-centredness

- Quality improvement

- Safety

- Timeliness

\subsection{Roles and Responsibilities}

\subsubsection{Role of the Ministry of Health at National Level}

The Ministry of Health shall:

- Oversee and facilitate implementation of the Policy at National and County levels;

- Ensure that there is adequate capacity in terms of staffing, equipment and supplies;

- Develop a comprehensive Plan of Action for the implementation of this Policy;

- Disseminate the ASRH Policy;

- Set standards and regulatory mechanisms;

- Regulate and co-ordinate ASRH training, information sharing and service delivery;

- Co-ordinate activities supported by development partners;

- Mobilize and allocate resources for ASRH programs;

- Facilitate adolescent data disaggregation through revision of existing data capture tools in the health facilities and sensitization of different stakeholders including the media;

- Strengthen the school health program.

The Ministry of Health shall collaborate closely with the MoEST for in-school adolescents who form the largest proportion of adolescents. The Joint Interagency Coordinating Committee (JICC) shall be the key mechanism for involving other ministries and development partners in coordinating resource mobilization and allocation. 
The Reproductive Health Inter-agency Coordinating Committee ( $\mathrm{RH}-\mathrm{ICC}$ ) and ASRH Technical Working Group (ASRH-TWG) shall be the mechanism for involving stakeholders to review and revise the ASRH Policy and action plan. It will also standardize and review implementation protocols, guidelines and procedures.

The Ministry of Health shall ensure collaboration among departments and divisions within and outside the ministry as identified in sub-section 6.3 .3 and encourage these ministries/agencies to mainstream ASRH issues in their core functions. The $\mathrm{MoH}$ shall also ensure meaningful participation of adolescent representatives in the $\mathrm{RH}-\mathrm{ICC}$ and policy implementation.

\subsubsection{Role of Ministry of Health at County Level}

County governments are responsible for health service delivery at the county level. Within the devolved governance structure, the county governments shall allocate resources towards implementation of the ASRH Policy. The planning, implementation, supervision and coordination of all ASRH program activities shall be undertaken by:

- The County Health Management Teams (CHMT),

- County Hospital Management Teams,

- Sub-County Health Management Teams (SCHMT),

- Primary care facility management teams; and

- Community units.

The county health committees, county hospital boards, primary care facility management committees and community health committees shall play an oversight role on $\mathrm{ASRH}$ matters, including resource mobilization, ensuring high quality of services as well as monitoring and evaluation. The county and sub-county health stakeholders' forums and the community dialogue days shall provide avenues for partnership and public participation in ASRH issues. The Ministry of Health shall ensure collaboration with key departments within and outside the ministry and encourage relevant agencies to mainstream $\mathrm{ASRH}$ issues in their core functions.

\subsubsection{Roles of Other Ministries and State Agencies}

A multi-sectoral approach shall be promoted in the implementation of the Policy. The following ministries and state agencies shall be involved: 


\section{Ministry of Education, Science and Technology (MOEST)}

- Implement AACSE in-line with the Education Sector Policy on HIV and AIDS (2013)

- Support utilization of ICT and other innovative approaches in delivery of ASRH information

- Ensure implementation of the Education Re-entry Policy for adolescents

- Facilitate provision of information to parents on sexual and reproductive health of adolescents within the school set-up

- Support implementation of school health programs

- Strengthen health referral system

- Support implementation of adolescent-related policies and guidelines

- Strengthen network of adolescents living with HIV

- Support treatment literacy for adolescent living with HIV

- Strengthen partnership with the $\mathrm{MoH}$ to provide ASRH information and services in schools

\section{The National \\ Treasury}

- Allocate financial resources for implementation of the Policy

- Improve fiscal responsibility

\section{Ministry of Devolution and Planning}

(Directorate Directorate of Gender, NCPD, KNBS, Anti- FGM Board)
- Support policy advocacy, resource mobilization and generation of data/information

- Integrate ASRH into youth empowerment programs

- Support gender mainstreaming in all ASRH and related programs

- Ensure implementation of the Prohibition of FGM Act (2011) and other ASRH related acts

- Support advocacy on elimination of SGBV

- Monitor anti-FGM interventions

\section{NACADA}

- Enact and ensure enforcement of laws that protect adolescents with regards to alcohol and substance abuse

- Create awareness on harmful effects of drugs and substance abuse

- Provide age-sex disaggregated data for alcohol, drug and substance abuse for decision making 


\begin{tabular}{|c|c|}
\hline $\begin{array}{l}\text { National } \\
\text { Human Rights } \\
\text { Institutions } \\
\text { (Commissions) }\end{array}$ & $\begin{array}{l}\text { - Investigate violations of SRH rights } \\
\text { - Receive complaints on violations of SRH rights } \\
\text { - Monitor implementation of ASRH commitments and } \\
\text { obligations }\end{array}$ \\
\hline $\begin{array}{l}\text { Ministry of } \\
\text { Information } \\
\text { Communication } \\
\text { and Technology } \\
\text { (Communication } \\
\text { Authority of } \\
\text { Kenya) }\end{array}$ & $\begin{array}{l}\text { - Support utilization of ICT in delivery of ASRH } \\
\text { information } \\
\text { - Regulate media content on sexual and reproductive } \\
\text { health information }\end{array}$ \\
\hline $\begin{array}{l}\text { Law Enforcement } \\
\text { Agencies } \\
\text { (National } \\
\text { Police Service, } \\
\text { Judiciary, } \\
\text { Internal Security, } \\
\text { HIV tribunal, } \\
\text { Office of } \\
\text { the Director } \\
\text { of Public } \\
\text { Prosecutions } \\
\text { (ODPP)) }\end{array}$ & $\begin{array}{l}\text { Enforce laws and administer justice to protect } \\
\text { adolescents }\end{array}$ \\
\hline $\begin{array}{l}\text { Ministry of } \\
\text { Labour, Social } \\
\text { Security and } \\
\text { Services } \\
\text { (National Council } \\
\text { for Children } \\
\text { Services, } \\
\text { Directorate } \\
\text { of Children } \\
\text { Services, } \\
\text { National Council } \\
\text { for Persons with } \\
\text { Disability) }\end{array}$ & $\begin{array}{l}\text { - Protect adolescents against harmful cultural } \\
\text { practices, child marriages and child labor } \\
\text { - Protect adolescents against child marriages and } \\
\text { trafficking } \\
\text { - Ensure greater livelihood opportunities for } \\
\text { adolescents in line with existing laws }\end{array}$ \\
\hline
\end{tabular}




\begin{tabular}{|c|c|}
\hline $\begin{array}{l}\text { Ministry of } \\
\text { Sports, Culture } \\
\text { and the Arts }\end{array}$ & Support and integrate ASRH in their programs \\
\hline $\begin{array}{l}\text { Ministry of } \\
\text { Transport and } \\
\text { Infrastructure }\end{array}$ & $\begin{array}{l}\text { - Improve physical accessibility to health facilities } \\
\text { - Support and integrate ASRH in their programs }\end{array}$ \\
\hline $\begin{array}{l}\text { Ministry of } \\
\text { Agriculture, } \\
\text { Livestock and } \\
\text { Fisheries }\end{array}$ & Support and integrate ASRH in their programs \\
\hline $\begin{array}{l}\text { Ministry of } \\
\text { Environment, } \\
\text { Water and } \\
\text { Natural } \\
\text { Resources }\end{array}$ & Support and integrate ASRH in their programs \\
\hline Parliament & $\begin{array}{l}\text { - Support allocation of resources for implementation } \\
\text { of the Policy } \\
\text { - Support implementation of the Policy in their areas } \\
\text { of jurisdiction }\end{array}$ \\
\hline
\end{tabular}




\begin{tabular}{|l|}
\hline Adolescents \\
\hline $\begin{array}{l}\text { NGOs, CSOs, } \\
\text { CBOs, FBOs and } \\
\text { Private Sector }\end{array}$ \\
\hline
\end{tabular}

\section{Development partners}

Communities, families and individuals
- Champion adolescent SRH interests through existing relevant structures at all levels

- Participate meaningfully in research, policy, planning and program implementation

- Special provisions will be made to foster participation and inclusion of adolescent girls

- Support provision of SRH information and services to adolescents and communities

- Support research and ASRH Policy formulation and dissemination

- Build community and stakeholder support for adolescent SRH policies and program

- Support sustainable program seeking to empower adolescents

- Meaningfully involve adolescents in policy formulation, program design, implementation, research and M\&E

- Advocate and mobilize resources for policy implementation

- Special efforts will be made to empower adolescent girls and boys who are especially vulnerable

- Mobilize resources for policy implementation

- Provide technical assistance for ASRH policies and program

- Provide SRH information to adolescents

- Support adolescent SRH policies and program

- Mobilize resources

- Participate in planning, implementation and M\&E of ASRH program 


\begin{tabular}{|c|c|}
\hline $\begin{array}{l}\text { Training and } \\
\text { research } \\
\text { Institutions } \\
\text { (Medical } \\
\text { Schools and } \\
\text { Colleges and } \\
\text { other Training } \\
\text { and Research } \\
\text { Institutions) }\end{array}$ & $\begin{array}{l}\text { - Enhance adolescent SRH content in nursing and } \\
\text { medical curricula at both pre- and in-service levels } \\
\text { - Conduct continuous research on ASRH and generate } \\
\text { information for decision making including policy } \\
\text { revision and/or development }\end{array}$ \\
\hline Media & $\begin{array}{l}\text { - Advocate and create public awareness on matters } \\
\text { related to ASRH } \\
\text { - Regulate media content for adolescents }\end{array}$ \\
\hline $\begin{array}{l}\text { Professional } \\
\text { associations } \\
\text { and regulatory } \\
\text { bodies }\end{array}$ & $\begin{array}{l}\text { - Advocate on ASRH } \\
\text { - Discipline members who violate code of conduct on } \\
\text { matters relating to ASRH } \\
\text { - Undertake research and knowledge sharing on ASRH } \\
\text { - Provide regulation and guidance on ASRH matters }\end{array}$ \\
\hline
\end{tabular}

\subsection{Monitoring and Evaluation}

The $\mathrm{MoH}$ shall provide overall strategic leadership in monitoring and evaluating implementation of the Policy with technical assistance from a multi-sectoral technical working group that includes development partners. An M\&E framework for assessing implementation and impact shall be established based on the goals and objectives of the Policy and targets set in the Plan of Action. The $\mathrm{MoH}$ and partners shall mobilize sufficient resources to support M\&E of the Policy and its Plan of Action.

The M\&E framework for the Policy shall link to MoH institutional M\&E framework and other key M\&E frameworks including the Health Management Information System (HMIS). The Policy shall advocate for integration of ASRH relevant indicators into the National Integrated Monitoring and Evaluation System and other relevant M\&E frameworks. State and non-state actors shall align their projects and or programs to the MoH M\&E framework. 
The Ministry of Health shall ensure continuous monitoring of the Policy implementation through routine data collection using HMIS and support supervision. The Policy shall promote collection, analysis and utilization of age and sex disaggregated data for adolescents. The Ministry of Health shall support capacity building of program managers, planners and service providers on data utilization for decision-making.

The Ministry of Health shall provide technical support to KNBS and other relevant research institutions to ensure inclusion of ASRH indicators in periodic population-based surveys and research.

The monitoring and evaluation of the Policy shall be guided by the indicators and targets below.

\begin{tabular}{|c|c|c|c|c|}
\hline \multirow[t]{2}{*}{ Indicator } & \multirow[t]{2}{*}{ Baseline } & \multicolumn{2}{|c|}{ Target } & \multirow{2}{*}{$\begin{array}{c}\text { Source of } \\
\text { Data }\end{array}$} \\
\hline & & 2020 & 2025 & \\
\hline $\begin{array}{l}\text { 1. Age at sexual debut } \\
\text { among 12-14 years } \\
\text { olds }{ }^{39}\end{array}$ & 10 years & 15 years & 18 years & KAIS \\
\hline $\begin{array}{l}\text { 2. Teenage pregnancy } \\
\text { among adolescent } \\
\text { women } 15-19 \text { years } \\
\text { (percent) }\end{array}$ & $\begin{array}{l}18.0 \\
(K D H S \\
2014)\end{array}$ & 12.0 & 10.0 & KDHS \\
\hline $\begin{array}{l}\text { 3. CPR for any } \\
\text { contraceptive } \\
\text { method among } \\
\text { adolescent women } \\
\text { (15-19 years) } \\
\text { (percent) }\end{array}$ & $\begin{array}{l}40.2 \\
(\mathrm{KDHS} \\
2014)\end{array}$ & 50.0 & 55.0 & KDHS \\
\hline $\begin{array}{l}\text { Condom use at } \\
\text { sexual debut for 15- } \\
24 \text { years olds }\end{array}$ & $\begin{array}{l}67 \% \text { (women) } \\
58 \% \text { (men) }\end{array}$ & $\begin{array}{l}75.0 \\
65.0\end{array}$ & $\begin{array}{l}80.0 \\
75.0\end{array}$ & $\begin{array}{l}\text { KDHS \& } \\
\text { KAIS }\end{array}$ \\
\hline $\begin{array}{l}\text { 4. Youth-friendly } \\
\text { services ( } \% \text { facilities } \\
\text { offering) }\end{array}$ & $\begin{array}{l}10.0 \\
\text { (SARAM } \\
2013)\end{array}$ & 30.0 & 50.0 & SARAM \\
\hline
\end{tabular}




\begin{tabular}{|c|c|c|c|c|c|}
\hline 5. & $\begin{array}{l}\text { Prevalence of female } \\
\text { genital mutilation } \\
\text { among } 15-19 \text { year } \\
\text { olds (percent) }\end{array}$ & $\begin{array}{l}11.4 \\
(\mathrm{KDHS} \\
2014)\end{array}$ & 8.0 & 5.0 & KDHS \\
\hline 6. & $\begin{array}{l}\text { Comprehensive } \\
\text { knowledge about } \\
\text { HIV among 10-14 } \\
\text { year olds (percent) }\end{array}$ & $\begin{array}{l}17.4 \\
\text { (KAIS 2012) }\end{array}$ & 40.0 & 60.0 & KAIS \\
\hline 7. & $\begin{array}{l}\text { Knowledge of HIV } \\
\text { prevention among } \\
\text { adolescent girls } \\
15-19 \text { year olds } \\
\text { (percent) }\end{array}$ & $\begin{array}{l}49.0 \\
\text { (KDHS } \\
2014)\end{array}$ & 60.0 & 75.0 & KDHS \\
\hline 8. & $\begin{array}{l}\text { Knowledge of HIV } \\
\text { prevention among } \\
\text { adolescent boys } \\
15-19 \text { year olds } \\
\text { (percent) }\end{array}$ & $\begin{array}{l}57.70 \\
(\mathrm{KDHS} \\
2014)\end{array}$ & 65 & 80.0 & KDHS \\
\hline 9. & $\begin{array}{l}\text { HIV incidence } \\
\text { among } 15-19 \text { year } \\
\text { olds (percent) } \\
\text { HIV prevalence } \\
\text { among 15-24 year } \\
\text { old males }\end{array}$ & $\begin{array}{l}0.9 \\
\text { (KAIS 2012) } \\
1.7 \\
\text { (Kenya HIV } \\
\text { Estimates) }\end{array}$ & 1.3 & 1.0 & $\begin{array}{l}\text { Kenya HIV } \\
\text { Estimates }\end{array}$ \\
\hline & $\begin{array}{l}\text { HIV prevalence } \\
\text { among 15-24 year } \\
\text { old females }\end{array}$ & $\begin{array}{l}2.8 \\
\text { (Kenya HIV } \\
\text { Estimates) }\end{array}$ & 2.4 & 2.0 & $\begin{array}{l}\text { Kenya HIV } \\
\text { Estimates }\end{array}$ \\
\hline 10 & $\begin{array}{l}\text { SGBV among } \\
\text { adolescent women } \\
\text { 15-19 years (percent) }\end{array}$ & $\begin{array}{l}4.2(\mathrm{KDHS} \\
2014)\end{array}$ & 2.0 & 1.0 & KDHS \\
\hline
\end{tabular}




\section{References}

1. Ministry of Devolution and Planning, Vision 2030 Kenya, (2007)

2. dictionary.reference.com/browse/abortion (July 2015)

3. www.who.int/topics/child_abuse/en/World Health Organization (2015)

4. http://www.unicef.org/infobycountry/stats_popup5.html

5. www.who.int/about/definition/en/print.html (2015)

6. http://www.unicef.org/lifeskills/index_7308.html (2015)

7. World Health Organization, Framework of Engagement with Non-State Actors. Sixty-Seventh World Health Assembly Provisional Agenda item 11.3 (2014)

8. http://www.unicef.org/infobycountry/stats_popup5.html (2015)

9. https://www.unodc.org/southeastasiaandpacific/en/topics/illicit-trafficking/humantrafficking-definition.html (2015)

10. Kenya National Bureau of Statistics, Kenya National Housing and Population Census (2009)

11. United Nations Population Fund (UNFPA) and Population Council, Investing when it Counts: Generating the evidence base for policies and programs for very young adolescents; Guide and tool kit (2006)

12. Kenya National Bureau of Statistics, ICF Macro. Kenya Demographic and Health Survey 2008-09. Calverton, Maryland: KNBS and ICF Macro, (2010)

13. Obare F, Birungi $\mathrm{H}$, et al., Levels, trends and determinants of contraceptive use among adolescent girls in Kenya: APHIA II OR Project in Kenya. Nairobi, Kenya: Population Council (2011)

14. Kenya National Bureau of Statistics, Kenya Demographic and Health Survey, Key Indicators Report (2014)

15. Kenya National Bureau of Statistics, Performance Monitoring and Accountability 2020 Family planning Indicator Brief (2014)

16. Ministry of Youth Affairs (MOYAS), Youth Dialogue Tool (2011)

17. Gessessew A, Mesfin M, Genitourinary and rectovaginal fistulae in Adigrat Zonal Hospital, Tigray, north Ethiopia. Ethiop Med J 2003; 41:123-0.

18. Chandra-Mouli V, McCarraher DR, Phillips SJ, et al. Contraception for adolescents in low and middle income countries: needs, barriers, and access. Reprod Health 2013; 11:1.

19. Kalanda BFB, Verhoeff FHF, Chimsuku LL, et al. Adverse birth outcomes in a malarious area. Bull Entomol Res 2006; 134:659-66.

20. Mayor, S, Pregnancy and childbirth are leading causes of death in teenage girls in developing countries. British Medical Journal Vol. 328 (2004)

21. African Population and Health Research Center (APHRC), Ministry of Health ( $\mathrm{MOH}$ ), Ipas, Guttmacher Institute, Incidence and Complications of Unsafe Abortions in 
Kenya: Key Findings of a National Study. Nairobi (2013)

22. United Nations Population Fund (UNFPA), Needs Assessment of Obstetric Fistula in Kenya (2004)

23. Muganda-Onyando Rosemarie and Omondi M, Down the Drain: Counting the Cost of Teenage Pregnancy and School Dropout in Kenya. Center for the Study of Adolescents (2008)

24. World Health Organization. Position paper on mainstreaming adolescent pregnancy in efforts to make pregnancy safer [Internet]. Geneva: World Health Organization, 2010. http://www.who.int

25. Mallé D, Ross DA, Campbell OM, et al. Institutional maternal mortality in Mali. Int J Gynaecol Obstet1994; 46: 19-26. [PubMed]

26. National AIDS and STI Control Programme (NASCOP), Kenya. Kenya AIDS Indicator Survey 2012: Final Report.

Nairobi, NASCOP. June 2014.

27. McKinnon LR1, Gakii G, Juno JA, Izulla P, Munyao J, Ireri N, Kariuki CW, Shaw SY, Nagelkerke NJ, Gelmon L, Musyoki H, Muraguri N, Kaul R, Lorway R, Kimani J.Remove the underlines (2014), High HIV risk in a cohort of male sex workers from Nairobi, Kenya. Sex Transm Infect. 2014 May; 90(3):237-42. doi: 10.1136/ sextrans-2013-051310. Epub 2013 Dec 13.

28. Douglas T Fleming, Judith $\mathrm{N}$ Wasserheit, From epidemiological synergy to public health policy and practice: the contribution of other sexually transmitted diseases to sexual transmission of HIV infection, Sex Transm Inf 1999;75:3-17

29. World Health Organization, Global Prevalence and Incidence of Selected Curable STI: Overview and Estimates. (2001)

30. United Nations Children's Fund, Violence against Children in Kenya: Findings from a 2010 National Survey. Summary Report on the Prevalence of Sexual, Physical and Emotional Violence: Context of Sexual Violence, and Health and Behavioral Consequences of Violence Experienced in Childhood. Nairobi, Kenya. (2012)

31. Hindin, Michelle $\mathrm{J}$ et al, Intimate Partner Violence among Couples in $10 \mathrm{DHS}$ Countries: Predictors and Health Outcomes. DHS Analytical Studies No. 18. Calverton, Maryland, USA: Macro International Inc (2008)

32. Population Reference Bureau, Gender-based Violence : Impediment to Reproductive health (2010)

33. www.nacada.go.ke/.../17-alcohol-drug-abuse-policy-legislation-implementation, July 2015

34. www.ijern.com/journal/2015/January-2015/52.pdf, July 2015

35. National Authority for the Campaign against Alcohol and Drug Abuse (NACADA), Rapid Situation Assessment of the Status of Drug and Substance Abuse in Kenya (2012)

36. World Health Organization, Risk and Protection Factors Affecting Adolescent Reproductive Health in Development Countries. Summary (2004)

37. National Council for Law Reporting, Prohibition of FGM Act 2011 (2011) 
38. World Health Organization, Understanding and addressing Violence against Women: Female Genital Mutilation. (2012)

39. National Council for Population and Development, Kenya Population Situational Analysis (2013)

40. Population Council, The Adolescent Experience In-depth: Using Data to Identify and Reach the Most Vulnerable Young People (2010)

41. Nour, N. M., Health Consequences of Child Marriage in Africa. Perspective: Child Marriage in Africa. Emerging Infectious Diseases. Volume 12 No. 11 (2006)

42. Beguy D, Mumah J, Wawire S, Muindi K, Gottschalk L and Kabiru CW, "Status Report on the Sexual and Reproductive Health of Adolescents Living in Urban Slums in Kenya," STEP UP Technical Working Paper. Nairobi. African Population and Health Research Center (2013)

43. African Population and Health Research Center (APHRC) (2014), Population and Health Dynamics in Nairobi's Informal Settlements: Report of the Nairobi Crosssectional Slums Survey (NCSS) 2012. Nairobi

44. Kenya National Bureau of Statistics and ILO/IPEC, Kenyan National Integrated Household Survey 2005/2006: Child Labour Analytical Report (2008)

45. Fassa, A.G., Health Benefits of Eliminating Child Labour. ILO/IPEC Working Paper (2003)

46. National Coordinating Agency for Population and Development - NCAPD and Kenya National Bureau of Statistics (KNBS), Kenya National Survey for Persons with Disabilities Main Report. Nairobi (2008)

47. Mumah J, Kabiru CW, Mukiira C, Brinton J, Mutua M, Izugbara C, Birungi H, and Askew I, Unintended Pregnancies in Kenya: A Country Profile. STEP UP Research Report. Nairobi: African Population and Health Research Center (2014)

48. Birungi, $\mathrm{H}$. et al, Sexual and Reproductive Health Needs of Adolescents living with HIV in Kenya. Nairobi: APHIA II OR Project in Kenya/ Population Council (2011)

49. National AIDS Control Council and National AIDS and STI Control Programme (2014), Kenya HIV Estimates

50. Kilonzo, N., Presentation on NACC made during UNICEF Partners' Meeting held on 5th Sept, 2014 (2014)

51. Obare, F, Anke van der Kwaak, and Birungi, H. Factors associated with unintended pregnancy, poor birth outcomes and post-partum contraceptive use among HIV-positive female adolescents in Kenya. BMC Women's Health 2012, 12:34 doi:10.1186/1472-6874-12-34 (2012)

52. Clark, $\mathrm{S}$ et al, Protecting Young Women from HIV/AIDS: The Case against Child and Adolescent Marriage. International Family Planning Perspectives 32(2): 79-88 (2006) 
53. Glynn, JR et al, Why Do Young Women Have Much Higher Prevalence of HIV than Young Men? A Study in Kisumu, Kenya and Ndola, Zambia. AIDS, Suppl 4: S51-60 (2001)

54. Mumah J, Kabiru CW, Izugbara C, and Mukiira C "Coping with unintended pregnancies: Narratives from adolescents in Nairobi's slums” STEP UP Research Report Nairobi: African Population and Health Research Center. (2014)

55. Clark, S., Early marriage and HIV risks in sub-Saharan Africa. Studies in Family Planning 35, 149-160. (2004)

56. Mathur, S. et al, Too Young to Wed: The Lives, Rights and Health of Young Married Girls. International Center for Research on Women (2003)

57. United Nations Education Fund, Early Marriage: A Harmful Traditional Practice - A Statistical Exploration (2005)

58. Juma, M. et al, Situational Analysis of the Sexual and Reproductive Health and HIV Risks and Prevention Needs of Older Orphaned and Vulnerable Children in Nyanza Province, Kenya. Population Council, Nairobi (2007)

59. National Council for Population and Development, Kenya Population Situation Analysis .http://countryoffice.unfpa.org/kenya/drive/FINALPSAREPORT.pdf (2013)

60. United Nations High Commissioner for Refugees, Kenya Fact Sheet. http://www. unhcr.org/524d84b99.html (2014)

61. Austin et al. (2008), Reproductive Health: A Right for Refugees and Internally Displaced Persons. http://www.rhm-elsevier.com/article/S0968-8080(08)31351-2/ fulltext

62. Ministry of Health, Service Availability and Readiness Assessment Mapping (SARAM) (2013) 


\section{Annex 1}

The members of the taskforce:

\begin{tabular}{|c|c|}
\hline Dr. Bartilol Kigen & $\mathrm{MOH} / \mathrm{RMHSU}$ \\
\hline Anne K. Njeru & $\mathrm{MOH} / \mathrm{RMHSU}$ \\
\hline Mary Magubo & $\mathrm{MOH} / \mathrm{RMHSU}$ \\
\hline Dr. Jeanne Patrick & $\mathrm{MOH} / \mathrm{RMHSU}$ \\
\hline Helgar Musyoki & $\mathrm{MOH} / \mathrm{NASCOP}$ \\
\hline Rose Mwongera & MOH/Policy \\
\hline Dr. Annie Mwangi & $\mathrm{MOH} / \mathrm{NCAHU}$ \\
\hline Margret Mwirigi & MOEST \\
\hline Seth Omondi & NCPD \\
\hline Catherine Ndei & NCPD \\
\hline Dr. Joyce Lavussa & WHO \\
\hline Batula Abdi & UNFPA \\
\hline Dr. Dan Okoro & UNFPA \\
\hline Jane Kamau & UNESCO \\
\hline MaqC Eric Gitau & UNICEF \\
\hline Francis Mutua & Youth Advisory Panel (YAP) - UNFPA \\
\hline Pamela Onduso & Pathfinder International \\
\hline Colette Ajwang' & Population Reference Bureau \\
\hline Dr. Harriet Birungi & Population Council \\
\hline Dr. Eunice Muthengi & Population Council \\
\hline Kigen Korir & Sexual Reproductive Health and Rights Alliance \\
\hline Chelimo Keter & LVCT Health \\
\hline Dr. Joyce Mumah & APHRC \\
\hline Christine Ochieng' & Federation of Women Lawyers (FIDA) \\
\hline Violet Murunga & African Institute for Development Policy \\
\hline Maureen Kuyoh & Consultant \\
\hline
\end{tabular}


The review and revision of the Adolescent Sexual and Reproductive Health Policy was supported by the United Nations Population Fund (UNFPA) under the Country Program of Assistance to Kenya; United States Agency for International Development (USAID) through IDEA Project implemented by the Population Reference Bureau (PRB) and Department for International Development (DFID) through Strengthening Evidence for Programming on Unintended Pregnancy (STEP UP) Research Program Consortium.



